\title{
SURGICAL STAGING IN EARLY OVARIAN CANCER
}

\author{
Stanislav Slavchev, Elis Ismail \\ Clinic of Gynecology, St. Anna University Hospital of Varna
}

\begin{abstract}
Ovarian cancer can be intraoperatively staged only. This staging is based on intraoperative findings and histological postoperative result. In early-staged ovarian cancer, it is essential to exclude a higher FIGO stage as a result of intraoperative staging. This review presents the most significant aspects of the staging process and the importance of surgical treatment of early ovarian cancer.
\end{abstract}

Key words: ovarian cancer, intraoperative staging, FIGO system, borderline tumours, prognostic factors

Ovarian cancer ranks third in incidence among malignant neoplasms of the female genital tract. In Bulgaria, its morbidity rates increases from 12,0 to 17,7 per 100,000 women during the last 20 years. The disease is detected at advanced III and IV FIGO stages in about $70-75 \%$ of the patients. Ovarian cancer has the most unfavourable prognosis when compared to all malignancies of the female genital tract. According to the mortality rate for stage I-IV, it is the primary cause of death from genital cancer. In the USA, it is on the sixth place in the structure of female cancer incidence and on the fifth one as a cause of death from cancer in women after breast cancer, lung cancer, colorectal cancer and lymphoma. Despite the significant advances in surgical staging, multi-agent chemotherapy with platinum, new chemotherapeutic agents, radical cytoreduction and improved surgical techniques, five-year survival for all stages of ovarian cancer remains a constant value of $39 \%$ over the past 35 years. There is an increased incidence rate of ovarian cancer worldwide, a

\author{
Address for correspondence: \\ Stanislav Slavchev, MD \\ Clinic of Gynecology, \\ St. Anna University Hospital of Varna \\ 100A Tsar Osvoboditel Blvd, 9002 Varna, Bulgaria \\ e-mail: st_slavchev@abv.bg
}

Received: August 30, 2012

Accepted: March 04, 2013 prolonged life expectancy in developed countries, and a lack of a common screening method. More and more patients are diagnosed with advanced disease, and five year survival in III-IV FIGO stage is $12-20 \%$.

The average age of patients with borderline tumours is approximately 46 years $(1,16,17)$. Eightyto-ninety percent of ovarian cancers, including borderline forms, occur after the age of 40 years, whereas $30-40 \%$ of malignancies do after the age of 65 years. The chance that a primary epithelial tumour will be of borderline or invasive malignancy in a patient younger than 40 years is approximately 1:10, however, after that age it rises to 1:3 $(1,16)$. Less than $1 \%$ of epithelial ovarian cancers occur before the age of 20 years, with two thirds of ovarian malignancies in such patients being germ cell tumours.

Ovarian malignancies are staged according to the FIGO system. It is based on findings at surgical exploration. A preoperative evaluation should exclude the presence of extraperitoneal metastases. The importance of the complete surgical staging originates the fact that subsequent treatment is determined by the already established stage of the disease. In the patients in whom exploratory laparotomy does not reveal any macroscopic lesions on inspection and palpation of intraabdominal space, microscopic alterations should be searched for $(11,12)$. In the past, when there is no careful staging, the overall five-year survival of the patients at an apparent epithelial ovarian cancer of stage I is about 
$60 \%$ (2). Since then, five-year survival rates between 90 and $100 \%$ are reported for the properly staged patients at stage IA or IB $(4,13)$.

\section{Technique for surgical staging}

The ovarian tumour should be removed intactly, if possible, and examined histologically promptly. If the tumour is limited to the pelvis, thorough surgical staging should be performed involving the following steps (1):

1. Any free fluid, especially in the pelvic cul-desac, should be cytologically examined.

2. If there is no free liquid, peritoneal lavage should be done by instilling $50-100 \mathrm{~mL}$ of saline in the pelvic cul-de-sac, each paracolic gutter, and beneath each hemidiaphragm. The washing under the diaphragm can be facilitated by means of a rubber catheter attached to the syringe.

3. A systematic exploration of any intraabdominal surfaces and visceral organs is performed in a clockwise fashion from the cecum cephalad along the paracolic gutter and the ascending colon to the right kidney, the liver and gallbladder, the right hemidiaphragm, across the transverse colon to the left hemidiaphragm, down to the left paracolic gutter to the rectosigmoid colon. The small intestine should be inspected from Treitz's ligament to the cecum.

4. Any suspicious areas of adhesions on the peritoneal surface should be histologically examined. If there are no obvious lesions, multiple intraperitoneal biopsies should be taken. Tissue of the peritoneum of the pelvic culde sac, both paracolic gutters, the peritoneum over the bladder and the intestinal mesenteries should be taken for biopsy examination.

5. The diaphragm should be examined by taking biopsy or by scraping and obtaining the sample for cytological assessment. The biopsies can be facilitated by using the laparoscope and the associated biopsy instrument.

6. The omentum should be resected from the transverse colon by infracolic omentectomy. If the gastrocolic ligament is normal on palpation, it is not resected at all.
7. The retroperitoneal spaces should be explored to evaluate the pelvic and paraaortic lymph nodes. The retroperitoneal dissection is performed by incision of the peritoneum over the psoas muscles. This may be carried out only on the ipsilateral side for unilateral tumours. Any enlarged lymph nodes should be resected and promptly histologically examined. If no metastases are present, a formal pelvic lymphadenectomy should be performed.

In the patients with apparent stage I or II epithelial ovarian cancer, metastases occur in 3 of 10 cases of confined tumour to the pelvis. However, they may present with occult metastatic disease in the upper abdomen or the retroperitoneal lymph nodes (3-15,18). In a review of the literature (2), occult metastases are revealed in biopsies of the diaphragm in $7,3 \%$ of the patients, of the omentum in $8,6 \%$, of the pelvic lymph nodes in 5,9\%, of the aortic lymph nodes in $18,1 \%$ as well as in $26,4 \%$ of peritoneal lavages.

The importance of the careful surgical staging is emphasized by the findings of a cooperative American study (13), in which 100 patients with apparent stage I and II ovarian cancer referred for subsequent therapy undergo an additional surgical staging. A total of $28 \%$ of the patients initially believed to be at stage I present with a higher stage while $43 \%$ of those believed to be at stage II present with more advanced lesions. As a result of additional surgery, $31 \%$ of the patients are upstaged and $77 \%$ of the cases are reclassified as having stage III of the disease. The histological grade is a significant predictor of occult metastases. Sixteen-percent of the patients with grade 1 are upstaged, compared with $34 \%$ with grade 2 and $46 \%$ with grade 3 .

Surgery is the primary treatment of stage I epithelial ovarian carcinoma. The patients should undergo total abdominal hysterectomy, bilateral salpingo-oophorectomy, and surgical staging $(2,13)$. In certain cases, a unilateral oophorectomy may be performed. Based on operative findings and pathological assessment, the patients at stage I are divided into two categories -of low-risk and highrisk (Table 1). 
Table 1. Prognostic factors in early-staged epithelial ovarian cancer

\begin{tabular}{ll}
\hline Low-risk factors & High-risk factors \\
low tumour grade & high tumour grade \\
non-clear cell histological type & clear cell histological type \\
intact capsule & tumour growth through the capsule \\
no surface excrescences & presence of surface excrescences \\
no ascites & presence of ascites \\
negative peritoneal cytological findings & presence of malignant cells in washing fluid \\
absent rupture or intraoperative rupture & preoperative rupture \\
no dense adherence & presence of dense adherence \\
diploid tumor & aneuploid tumor
\end{tabular}

\section{Borderline tumours}

The surgical resection of the primary tumour is the main treatment option in borderline neoplasms. There is no evidence that subsequent chemotherapy or radiation therapy improves patient's survival. After a determination of a borderline tumour on a frozen histologic section in premenopausal patients who desire preservation of their ovarian function, they may undergo conservative surgery such as a unilateral oophorectomy $(1,3,19)$. A study of patients with unilateral ovarian cystectomy for stage I borderline serous tumours (19) demonstrates that this conservative operation is safe, too. Relapses occur in $8 \%$ of the patients only, two to 18 years later on as the disease remains limited to the ovaries. These recurrences are associated with positive margins of the removed ovarian cyst. Thus the hormonal function and fertility can be preserved. For patients in whom an oophorectomy or cystectomy is performed and a borderline tumour is identified from the permanent histological sample, no additional immediate surgery is necessary any more.

\section{Stage I, low-grade and low-risk patterns}

Abdominal hysterectomy and bilateral salpingooophorectomy are appropriate treatment options for the patients with a thorough staging laparotomy and without any evidence of dissemination beyond the ovary. Uterus and contralateral ovary can be preserved in women with stage Ia, grade 1 disease who desire to preserve their fertility. Woman's status should be dynamically monitored by periodic examinations and serum CA125 level determinations. In general, the other ovary and the uterus are removed at child bearing completion.

The outcome of 656 patients with early-stage epithelial ovarian cancer was investigated (8). No patients with stage Ia, grade 1 cancer remaining not treated die of their disease. The conclusion is drawn that adjuvant radiation and chemotherapy are unnecessary. Furthermore, the Gynecologic Oncology Group performs two prospective, randomized national cooperative trials of adjuvant therapy in patients with localized ovarian carcinoma (20). There are no significant differences between the patients with stage Ia and Ib, grade I of disease, given no chemotherapy and those treated with melphalan with respect to either five-year disease-free survival (91 versus 98\%) or overall survival (94 versus 98\%). Comprehensive staging at the time of surgical resection can serve to identify those patients who can be followed without adjuvant chemotherapy.

\section{REFERENCES}

1. Berek, J. S. Epithelial ovarian cancer.- In: Practical gynecologic oncology. J. S. Berek, N. F. Hacker, eds. $3^{\text {rd }}$ ed. Philadelphia, Lippincott Williams \& Wilkins, 2000, 457-522.

2. Berek, J. S., N. F. Hacker. Staging and second-look operations in ovarian cancer.- In: Ovarian cancer. D. S. Alberts, E. A. Surwit, eds. Boston, Martinus Nijhoff, 1985, 109-127.

3. Bostwick, D. G., H. D. Tazelaar, S. C. Ballon, M. R. Hendrickson, R. L. Kempson. Ovarian epithelial 
tumors of borderline malignancy. A clinical and pathologic study of 109 cases.- Cancer, 58, 1986, No 9, 2052-2065.

4. Buchsbaum, H. J., S. Liftshitz. Staging and surgical evaluation of ovarian cancer.- Semin. Oncol., 11, 1984, No 3, 227-237.

5. Chen, S. S., L. Lee. Incidence of para-aortic and pelvic lymph node metastases in epithelial ovarian cancer.- Gynecol. Oncol., 16, 1983, No 1, 95-100.

6. Creasman, W. T., F. Rutledge. The prognostic value of peritoneal cytology in gynecologic malignant disease.- Am. J. Obstet. Gynecol., 110, 1971, No 6, 773-781.

7. Delgado, G., B. Chun, H. Caglar, F. Bepko. Paraaortic lymphadenectomy in gynecologic malignancies confined to the pelvis.- Obstet. Gynecol., 50, 1977, No 4, 418-423.

8. Guthrie, D., M. L. Davy, P. R. Phillips. Study of 656 patients with "early" ovarian carcinoma.- Gynecol. Oncol., 17, 1984, No 3, 363-369.

9. Keettel, W. C., E. E. Pixley, H. J. BuchsbaumJ. Experience with peritoneal cytology in the management of gynecologic malignancies.- Am. J. Obstet. Gynecol., 120, 1974, No 2, 174-182.

10. Knapp, R. C., E. A. Friedman. Aortic lymph node metastases in early ovarian cancer.- Am. J. Obstet. Gynecol., 119, 1974, No 8, 1013-1017.

11. Kornovski, Ya., G. Gorchev. Surgical treatment of ovarian cancer.- Oncologos, 2004, 16-21 (in Bulgarian).

12. Kornovski, Ya., R. Yaneva, D. Kornovski. Retroperitoneal approach and pelvic peritoneoectomy in surgical treatment of advanced ovarian cancer.- Akush. ginekol. (Sofia), 2006, No 6, 61-68 (in Bulgarian).

13. Lim-Tan, S. K., H. E. Cajigas, R. E. Scully. Ovarian cystectomy for serous borderline tumors: a followup study of 35 cases.- Obstet. Gynecol., 72, 1988, No $5,775-781$.
14. Piver, M. S., J. J. Barlow, S. B. Lele. Incidence of subclinical metastasis in stage I and II ovarian carcinoma.- Obstet. Gynecol., 52, 1978, No 1, 100-104.

15. Rosenoff, S. H., R. C. Young, T. Anderson, C. Bagley, B. Chabner, P. S. Schein, et al. Peritoneoscopy: a valuable staging tool in ovarian carcinoma.- Ann. Intern. Med., 83, 1975, No 1, 37-41.

16. Scully, R. E., R. H. Young, P. B. Clement. Tumors of the ovary, maldeveloped gonads, fallopian tube, and broad ligament.- In: Atlas of tumor pathology. Washington, Armed Forces Institute of Pathology, 1998 , Fascicle 23, $3^{\text {rd }}$ series.

17. Seidman, J. D., R. J. Kurman. Subclassification of serous borderline tumors of the ovary into benign and malignant types. A clinicopathologic study of 65 advanced stage cases.- Am. J. Surg. Pathol., 20, 1996, No 11, 1331-1345.

18. Yoshimuma, S., R. E. Scully, D. A. Bell, P. D. Taft. Correlation of ascitic fluid cytology with histologic findings before and after treatment of ovarian cancer.- Am. J. Obstet. Gynecol., 148, 1984, No 6, 716-721.

19. Young, R. C., D. G. Decker, J. T. Wharton, M. S. Piver, W. F. Sindelar, B. K. Edwards, et al. Staging laparotomy in early ovarian cancer.- JAMA, 250, 1983, No 22, 3072-3076.

20. Young, R. C., L. A. Walton, S. S. Ellenberg, H. D. Homesley, G. D. Wilbanks, D. G. Decker, et al. Adjuvant therapy in stage I and stage II epithelial ovarian cancer. Results of two prospective randomized trials.- New Engl. J. Med., 322, 1990, No 15, 1021-1027. 